\title{
Kadın Hastalıkları ve Doğum Uzmanlık ve Yan Dal Uzmanlık Öğrencilerinin Hastane Eğitim Ortamı Algılarının Değerlendirilmesi
}

\section{Evaluation of Hospital Education Environment Perceptions of Obstetrics and Gynecology Residents in Specialist and Subspecialty Training}

\author{
Mekin Sezik' (ORCID: 0000-0002-6989-081X) \\ Mehtap Savran ${ }^{2}$ (ORCID: 0000-0002-7933-0453) \\ Cüneyt Orhan Kara ${ }^{3}$ (ORCID: 0000-0003-2219-4283) \\ Mustafa Kemal Alimoğlu (ORCID: 0000-0002-0587-1177) \\ ${ }^{1}$ Süleyman Demirel Üniversitesi Tıp Fakültesi Kadın Hastalıkları ve Doğum Anabilim Dalı, Isparta \\ ${ }^{2}$ Süleyman Demirel Üniversitesi Tıp Fakültesi Tıbbi Farmakoloji Anabilim Dalı, Isparta \\ ${ }^{3}$ Pamukkale Üniversitesi Tıp Fakültesi Kulak Burun Boğaz Hastalıkları Anabilim Dalı, Denizli \\ ${ }^{4}$ Akdeniz Üniversitesi Tıp Fakültesi Tıp Eğitimi Anabilim Dalı, Antalya \\ Sorumlu Yazar: Prof. Dr. Mekin SEZIKK \\ Prof. Dr. Mekin SEZIKK \\ Süleyman Demirel Üniversitesi Tıp Fakültesi Kadın Hastalıkları ve Doğum AD Isparta, Turkiye \\ Telefon: +90-246-2119239 Fax:+902462371165 E-posta: msezik@yahoo.com
}

Anahtar Sözcükler: uzmanlık eğitimi, hastane içi eğitim ortamı, kadın hastalıkları ve doğum

Keywords: postgraduate training, hospital education environment, obstetrics and gynecology

Gönderilme Tarihi Submitted:17.07.2019

Kabul Tarihi

Accepted: 06.10.2019

\section{ÖZET:}

Giriş: Türkiye'de kadın hastalıkları ve doğum uzmanlık öğrencilerinin hastane içi eğitim ortamı algılarına dair kısıtlı veri mevcuttur. Mevcut araştırmada, Mezuniyet Sonrası Hastane Eğitim Ortamı Ölçeğinin (MESHEÖ), bir kadın hastalıkları ve doğum kliniğindeki asistan hekimlere uygulanarak eğitim ortamı algılarının saptanması amaçlanmıştır.

Gereç-Yöntem: Tek bir kadın hastalıkları ve doğum anabilim dalında aktif çalışan uzmanlık ve yan dal uzmanlık öğrencilerinin tümüne $(\mathrm{n}=19)$ MESHEÖ uygulandı. Maddeler ve alt başlıklar için dağılım ve skorlar hesaplandi.

Künye: Sezik M, Savran M, Kara C, Alimoğlu M. Kadın Hastalıları ve Doğum Uzmanlı ve Yan Dal Uzmanlı Öğrencilerinin Hastane Eğitim Ortamı Algllarının Değerlendirilmesi. Tip Ĕgitimi Dünyası. 2020;19(57):64-75 
Cinsiyet ve k1dem (ilk 2 y1l kıdemsiz, 2 yıldan sonra kıdemli) açısından Mann-Whitney U testi kullanılarak skorlar karşılaştırıldı. Ölçüm güvenirliği kestirimi için Cronbach alfa katsayısı hesaplandi.

Bulgular: Cronbach alfa katsayıs 0.938 ve ortalama toplam skor $85.8 \pm 24.8$ (olumlu ancak geliştirilmesi gereken eğitim ortamı) olarak hesaplandı. Mesleki özerklik, eğitim niteliği ve sosyal destek algılarına dair alt grup ortalama skorları ise sirasiyla $28.3 \pm 8.2$ (yetersiz), $33.4 \pm 11.0$ (nitelikli) ve $24.1 \pm 6.8$ (olumlu özellikleri daha baskın) idi. Kadın ve erkeklerin toplam ve alt grup ortalama skorları benzerdi (tüm karşılaştırmalar için $\mathrm{p}>0.05$ ). Kıdemli olanlarda, ilk 2 yılın içindekilere göre ortalama skor benzerken ( $p=0.087)$, sosyal destek ortalama skoru daha yüksekti $(p=0.039)$. Üç adet maddenin ortalama skoru 1 ve altındaydi: (i) Bilgilendirici bir asistan el kitabı vardır, (ii) $\mathrm{Bu}$ hastanede asistanlar için yeterli ve uygun asistan odası (özellikle de nöbet odası) vardır, (iii) Çalışma saatlerim haftalık yasal çalışma süresi ile uyumludur.

Sonuç: Ölçeğin uygulandığı klinikte uzmanlık eğitimi alan hekimlerin hastane içi eğitime dair algıları cinsiyetten bağımsız olarak genelde olumlu gözükmekle birlikte asistan el kitab1, nöbet odası, çalışma saatleri başta gelmek üzere birçok mesleki özerklik ve sosyal destek unsurunda iyileştirmelere ihtiyaç duyulmaktadır. MESHEÖ nispeten kolay uygulanabilir, kullanışlı ve güvenilir bir araç olarak mezuniyet sonrası eğitim programlarını değerlendirme ve iyileştirme amaçlı kullanılabilir.

\section{ABSTRACT:}

Background: Data on educational hospital environment perceptions of obstetrics and gynecology residents in Turkey are limited. The present study aims to evaluate the educational environment perceptions of residents in (sub)specialty training in an obstetrics and gynecology department
Methods: Postgraduate Hospital Educational Environment Measure (PHEEM) was administered to all presently working residents $(n=19)$ in specialty and subspecialty training at an obstetrics and gynecology department of a single university hospital. Item and subscale scores of gender and postgraduate experience groups were compared using Mann-Whitney $U$ test. The participants were classified into two groups regarding postgraduate experience as "novice" (postgraduate year 1 and 2) and "experienced" (postgraduate year 3 and above). Cronbach's alpha coefficient was calculated to estimate score reliability.

Results: The overall Cronbach's alpha coefficient and mean cumulative score was 0.938 and 85.8 \pm 24.8 (more positive than negative, but room for improvement), respectively. Mean subscale scores were $28.3 \pm 8.2$ for role of autonomy (negative view), $33.4 \pm 11.0$ for teaching (moving in the right direction), and $24.1 \pm 6.8$ for social support (more pros than cons). Cumulative and category scores did not differ regarding gender $(p>0.05$ for all $)$. Experienced group had similar mean cumulative $(p=0.087)$, but increased social perception scores $(p=0.039)$ compared to novice group. Mean scores of three items were extremely low $(<1)$ : (i) an informative junior doctor's handbook is available, (ii) this hospital has good accommodation facilities for junior doctors, especially when on call, and (iii) my working hours comply with legal requirements.

Conclusions: Hospital educational environment perceptions of physicians in (sub)specialty training are generally positive independent of gender in the reviewed department, while there is room for improvement of various role autonomy and social support components such as doctor's handbook, on call accommodation, and working hours. PHEEM seems to be a relatively practical, convenient, and reliable tool to evaluate and improve postgraduate medical training. 


\section{GíRIŞ}

Eğitim ortamı bir sinıfta, bir bölümde, bir fakültede veya bir üniversitede "olup biten her şey” olarak tanımlanmıştır (1). Roff ve McAleer, "hasta bina sendromu" ile analoji kurarak "hasta eğitim ortamı" da olabileceğini belirtmektedir (2). Klinik dallarda tıp uzmanlığı eğitimi, önemli oranda hastane ortamında gerçekleşmektedir. Hastane eğitim ortamında karmaşık etkileşimler söz konusu olup uzmanlık eğitiminde eğitim ortamı sadece uzmanlık eğitimini değil çok farklı süreçleri de etkileyebilmektedir. Uzmanlık öğrencilerinin hastane eğitim ortamlarının uygun eğitim için yeterli hale getirilmesi ile hasta güvenliği ve memnuniyetinde artış sağlandığına dair veriler bulunmaktadır $(3,4)$. Bu nedenle; hastane eğitim ortamının niteliğinin değerlendirilmesi son derece önemli olup, elde edilen veriler kullanılarak uzmanlık öğrencilerinin beklentileri ve görüşlerinin değişim süreci ile bütünleştirilmesi hedeflenmelidir (5).

Mezuniyet sonrası dönemde klinik eğitim ikliminin ölçülmesi amacı ile Roff ve arkadaşları tarafindan Mezuniyet Sonrası Hastane Eğitim Ortamı Ölçeği -MESHEÖ (Postgraduate Hospital Educational Environment Measure PHEEM) geliştirilmiştir $(6,7)$. Ölçeğin Türkçe geçerlik ve güvenirlik çalışması ise Balcığlu tarafindan gerçekleştirilmiştir (8).

İngilizce literatürde tek başına kadın hastalıkları ve doğum uzmanlık eğitim ortamını değerlendiren az sayıda araştırma mevcuttur (9-12). Amerika Birleşik Devletlerinde kadın hastalıkları ve doğum uzmanlık öğrencilerini içeren bir anket çalışmasında (10) hasta bakımının devamlılığı, iş tanımı belirsizliği ve hastane öğrenme ortamı başlıklarının program memnuniyetsizliği ile ilişkili olduğu belirtilmiştir. Avrupa'da jinekolojik onkoloji yan dal uzmanlık öğrencilerine yönelik gerçekleştirilen internet tabanlı bir anket çalışmasında, kliniğin akredite olması ve toplam eğitim y1lının daha iyi eğitim ortamı ile bağımsız olarak ilişkili olduğu saptanmıştır (9). İran'da doğum servisinde klinik eğitim alan ebelik öğrencileri, intörnler ve asistanların dahil edildiği bir nitel araştırmada ise eğitim ortamında yapılandırılmış eğitim yokluğu ve öğrencilerin duygusal yükünde artış gibi nedenlerle klinik eğitim ortamının olumsuz etkilendiği saptaması yapılmıştır (12). Son olarak da Hollanda'da 16 kadın hastalıkları ve doğum bölümünün dahil edildiği bir araştırmada, hastane eğitim ortamı skorlarının perinatal sonuçlar ile bağımsız bağıntı gösterdiği saptanmıştır (11). Ulaşabildiğimiz kadarı ile Türkiye'de sadece kadın hastalıkları ve doğum uzmanlık öğrencilerine yönelik hastane eğitim ortamı algısını değerlendiren bir çalışma alan yazında yer almamaktadır.

Bu çalışmada orta ölçekli bir klinikte eğitim alan kadın hastalıkları ve doğum uzmanlık ve yan dal uzmanlık öğrencilerinin hastane eğitim ortamı algılarının değerlendirilmesi planlanmıştır.

\section{GEREÇ VE YÖNTEM}

Araştırma, Süleyman Demirel Üniversitesi Tıp Fakültesi Kadın Hastalıkları ve Doğum Anabilim Dalında, anabilim dalı başkanlığı ve yerel klinik araştırmalar etik kurulunun yazılı onay1 ile gerçekleştirilmiştir (19.02.2019/60). Araştırma evreni, anılan anabilim dalında görevli kadın hastalıkları ve doğum veya yan dal uzmanlık eğitimine devam eden tüm hekimleri kapsamaktadır. Bu nedenle, ayrıca örneklem kullanılmamıştır.

MESHEÖ, toplam skoru 160 olan beşli Likert 
düzeneğinde 40 maddeden oluşmakta; mesleki özerklik, eğitimin niteliği ve sosyal destek algısı alt başlıklarını içermektedir. Toplam ve alt başlık skorları, maddelerin sıfırdan dörde kadar Likert derecesine göre puanlanması ve puanların toplanması ile hesaplanmaktadır. Ölçekte kullanılan beşli Likert skalasının yanıtları kesinlikle katıliyorum (4 puan), katılıyorum (3 puan), kararsızım (2 puan), katılmıyorum (1 puan), ve hiç katılmıyorum (0 puan) şeklinde puanlanmakta olup ölçek toplam skoru maddeler için dörtten sıfıra yapılan tercihlerin puan karşılıklarının toplanmasıyla hesaplanmaktadır. Olumsuz anlam yükü içeren dört madde için ( 7 , 8, 11 ve 13. maddeler) ayna görüntüsü şeklinde ters puanlama yapılmaktadır (8). Ölçekteki 40 maddenin toplam skoru 160 olup, toplam skor yüksekliği eğitim ortamının yeterli olmasını, alt boyut skorlarının yüksekliği ise üç farklı alt boyut için sırası ile mesleki özerlik algısının yeterli olmasını, eğitim niteliğinin yüksek olmasını ve sosyal destek algısının öğrenmeyi desteklemesini ifade etmektedir (8). Bunlara ait detaylar aşağıda verilmiştir.

Ölçek alt grup skorlarının şu şekilde değerlendirilmesi önerilmektedir: Mesleki özerklik alg1sı için 0-14 çok yetersiz, 15-28 yetersiz, 29-42 yeterli ve 43-56 mükemmel; eğitim niteliği algısı için 0-15 düşük nitelikli, 16-30 geliştirilmesi gerekir, 31-45 nitelikli ve 46-60 örnek eğiticiler; sosyal destek alg1sı için 0-11 yok, 12-22 memnuniyet verici özellikte değil, 23-33 olumlu özellikleri daha baskın ve 34-44 öğrenmeyi destekleyen bir ortam (8). MESHEÖ madde ortalama skorları, ilgili eğitsel alan hakkındaki genel alg1 hakkında da fikir verebilir. Üç buçuk ve üzerindeki bir skor olumlu bir ortam algısına işaret ederken 2 ve altındaki ortalamalar o alanda bir sorun olduğunu gösterebilir $(6,8)$.
Balcıoğlu tarafından Türkçe' ye uyarlanarak geçerlik ve güvenirlik çalışması yapılan MESHEÖ, Şubat 2019 tarihinde Süleyman Demirel Üniversitesi Kadın Hastalıkları ve Doğum Anabilim Dalı kadrosunda aktif çalışan uzmanlık ve yan dal uzmanlık öğrencilerinin tümüne (n=19) kapalı zarf içinde basılı şekilde verildi. Doğum sonrası izni kullanan iki kadın uzmanlık öğrencisi, iki aydan fazla süre boyunca hastane ortamında bulunmadığından, çalışma dişında tutuldu.

Ölçek uygulaması öncesinde tüm uzmanlık öğrencilerinin bulunduğu klinik ortamda, çalışmanın amacı hakkında tüm katılımcılara kısa sözel bilgilendirme yapılarak verilerin anonim olarak sadece araştırma amaçlı toplandığı vurguland1. Katılımcıların, ölçeği hastane ortamı dişında iken sakin ve yoğunlaşmış bir şekilde içtenlikle yanıtlamalarının beklendiği belirtildi. Doldurulan formların isim, soyadı veya benzeri tanımlayıcı bilgi yazılmaksızın kapalı zarfa konularak iki gün içinde araştırmacı olmayan bir kişiye (anabilim dalı sekreteri) teslim edilmesi istendi. Yan dal uzmanlık eğitimi gibi detaylı demografik veri talep edilmesinin, anonimliği kısıtlayarak sosyal istenirlik yanlılı̆̆ına yol açabileceği öngörüldügünden, basılı ölçek formlarında sadece eğitim (kıdem) y1lı ve cinsiyet sorguland1. Kapalı zarflar toplu halde sekreterlikten alınarak verilerin işlenmesi ve değerlendirilmesine geçildi.

Elde edilen veriler dijital ortama aktarılarak maddeler ve alt başlıklar için dağılım ve skorlar hesaplandı. Veriler, ortalama \pm standart sapma ve ortanca ile dağılım (minimum maksimum değerler) olarak değerlendirildi. Ölçüm güvenirliği kestirimi için Cronbach alfa katsayısı hesaplandı. Uzmanlık eğitiminin ilk iki yılı "kıdemsiz", iki yıldan sonraki dönem 
ise "kıdemli" şeklinde kategorize edildi. Cinsiyet ve kıdem bakımından puanların normal dağılıma uygunluğu Shapiro-Wilk testi ile değerlendirildi. $\mathrm{Bu}$ iki değişkene ait skorlar ise Mann-Whitney U testi kullanılarak karşılaştırıldı. Tüm analizlerde $\mathrm{p}$ değerinin 0.05 altında olması istatistiksel olarak anlamlı kabul edildi.

\section{BULGULAR}

Doğum izninde olan ve klinik ortamda bulunmayan 2 uzmanlık öğrencisi çalışmaya alınmadı. Biri dışında basılı ölçeklerin tümü doldurulmuş şekilde teslim edildi (katılım oranı: \%94.7). Araştırma evrenindeki bireylere ulaşma oranı ise \%85.7 (18/21) olarak hesaplandı. Kırk maddenin tümü için Cronbach alfa katsayısı 0.938 olarak hesapland. Maddeler tek tek incelendiğinde, ölçekten çıkarılması durumunda Cronbach alfa katsayısını 0.95 üzerine çıkaracak herhangi bir madde mevcut değildi. Katılımcıların \%53'ü kadın, \%47'si erkek, \%65'i k1demsiz ve \%35'i k1demli asistan olduğunu belirtmişti. Uzmanlık eğitiminin ilk, ikinci, üçüncü ve dördüncü yılında olan sirası ile 3 (\%17.6), 8 (\%47.1), 2 (\%11.8) ve 4 (\%23.5) öğrenci mevcuttu. İki formda k1dem ve cinsiyet belirtilemediğinden, bunlar istatistiksel karşılaştırmalarda analiz dışında bırakıldı.

Ölçek maddelerine verilen cevapların dağılımı ve maddelere verilen ortalama puanlar $( \pm$ standart sapma) Tablo 1'de gösterilmektedir. Üç adet maddenin ortalama puanı bir ve altındaydı: (i) Bilgilendirici bir asistan el kitabı vardır (0.61 \pm 0.91 ), (ii) $\mathrm{Bu}$ hastanede asistanlar için yeterli ve uygun asistan odası (özellikle de nöbet odası) vardır (0.89 \pm 1.28$)$, (iii) Çalışma saatlerim haftalık yasal çalışma süresi ile uyumludur (1.0 \pm 1.49). Bu üç madde için de katılımcıların yaklaşık \%60'ının "kesinlikle katılmıyorum” cevabını verdiği saptand. Sadece bir maddenin (bu klinikte etnik ayrımcılık vardır) ortalama puan1, negatif soru olması nedeniyle düzeltildiğinde, üçün üzerindeydi (3.38 \pm 1.03$)$. Diğer ortalama puanların tümü 1-3 aralığında idi.

Ölçek alt grup ortalama skorları ve bunların cinsiyet ile kıdeme göre dağılımı Tablo 2'de sunulmaktadir. Ortalama toplam skor 85.8 \pm 24.8 (olumlu ancak geliştirilmesi gereken eğitim ortamı: 81-120) olarak hesaplandı (Tablo $2)$. Alt gruplara ait ortalama skorlar ise mesleki özerklik için $28.3 \pm 8.2$ (yetersiz), eğitim niteliği için $33.4 \pm 11.0$ (nitelikli) ve sosyal destek algıları için $24.1 \pm 6.8$ (olumlu özellikleri daha baskın) olarak saptand1 (Tablo 2). Toplam skor ile mesleki özerklik, eğitim niteliği ve sosyal destek alt gruplarına dair skorların normal dağılım gösterdiği saptandı (Shapiro Wilk testi $\mathrm{p}$ değerleri sirasıyla $\mathrm{p}=0.99, \mathrm{p}=0.61, \mathrm{p}=0.85$ ve $p=0.78)$.

Tüm karşılaştırmalarda kadın ve erkeklerin toplam ve alt grup ortalama skorları benzerdi ( $p>0.05$, Tablo 2). Kidemli olanlarda, ilk iki yılın içindekilere göre ortalama skor benzerken $(\mathrm{p}=0.07)$, sosyal destek ortalama skoru daha yüksekti ( $p=0.039)$. Kıdemli olanlarda üç adet maddenin ortalama puan1, kıdemsiz olanlara göre daha yüksekti: (i) Bu hastanede asistanlar için yeterli ve uygun asistan odası (özellikle de nöbet odas1) vardır $(0.27 \pm 0.65$ 'e karş1lık 2.00 $\pm 1.55, \mathrm{p}=0.018$ ), (ii) Klinikteki k1demlilerim öğrenme firsatlarını iyi değerlendirirler (2.00 \pm 1.18 'e karşılık $3.16 \pm 0.75, \mathrm{p}=0.042$ ), iii) İşimden çok keyif alıyorum $(1.54 \pm 0.93$ 'e karş1lık $3.00 \pm 1.09, \mathrm{p}=0.019$ ).

\section{TARTIŞMA}

Mevcut araştırmada, üniversite hastanesi 
bünyesindeki orta ölçekli bir kadın hastalıkları ve doğum kliniğinde çalışan uzmanlık öğrencilerinin hastane eğitim algıları geçerlik ve güvenirliği önceden teyit edilmiş bir ölçek kullanılarak değerlendirilmiştir. Araştırmanın en önemli kısıtlığı, tek bir klinikte nispeten az sayıda katılımcı ile gerçekleştirilmiş olmasıdır. Ayrıca, mevcut araştırma herhangi bir nitel veri içermemektedir. Sonuçlar, sadece tek bir klinikte çalışan uzmanlık öğrencileri için genellenmiş olup diş geçerlik düşüktür. Türkiye'de aile hekimliği asistanlarının eğitim ortamı ile ilgili algılarının ve bu algıları etkileyen faktörlerin araştırılması amacı ile MESHEÖ kullanılarak gerçekleştirilen araştırma çalışmaları mevcuttur $(12,13)$. Bunlara rağmen, ulusal ve uluslararası alan yazında kadın hastalıkları ve doğum alanında bu güne kadar yapılan araştırmalar MESHEÖ ölçeğinin geçerleme çalışmalarıdır. Ölçeğin en önemli amacı eğitim ortamının değerlendirilmesi ve varsa mevcut sorunların ortaya konmasıdır. Bu araştırma da, bu amaçla kadın hastalıkları ve doğum alanına özgü ulaşabildiğimiz kadarı ile ilk çalışmadır.

Mevcut araştırmanın yürütüldüğü klinikte (Süleyman Demirel Üniversitesi Tıp Fakültesi, Isparta) uzmanlık öğrencilerinin mesleki özerklik algıların yetersiz olduğu saptandı. Hacettepe Üniversitesi Tıp Fakültesinde farklı dallardan 212 uzmanlık öğrencisinin dahil edildiği ve MESHEÖ kullanılarak klinik eğitim ortamlarına ilişkin algılarının değerlendirildiği bir çalışmada ise mesleki özerklik bağlamında "yeterli" ancak eğitim algısı bağlamında "yetersiz" şeklinde sonuçlara ulaşılmıştır (15). Hacettepe bulguları, bizim verilerimizle uyuşmamaktadır. Hollanda'daki tüm tıp fakültelerindeki (8 adet) kadın hastalıkları ve doğum klinik stajlarının MESHEÖ ve öğrencilerle görüşmeler kullanılarak değerlendirildiği bir karma yöntem araştırmada $(16,17)$ ortalama MESHEÖ skorlarının bölümler arasında farklılık gösterdiği saptanmıştır. Her kurum ve kliniğin, güçlü ve geliştirilmesi gereken yönlerini saptayarak bu konuda adımlar atması beklenmelidir $(17,18)$.

Mevcut çalışmamızın gerçekleştirildiği klinikte, asistan el kitabı konusunda yetersizlik saptanmıştır. Asistan el kitabı uygulaması, eğitimin standardizasyonu açısından önem taşımaktadır (19). Türkiye'de ortopedi ve travmatoloji uzmanlık öğrencilerinin algılarının değerlendirildiği geniş kapsamlı (857 katılımcı) bir anket çalışmasında da benzer sonuçlara ulaşılmıştır (20). Ortopedi ve travmatoloji asistanlarının yaklaşık üçte biri (\%37.3), uygulanan bir eğitim programının bulunmadığını belirtmiştir. Aynı çalışmada, asistan el kitabı uygulamasında da aksaklıklar saptanmıştır (20). İspanya'daki tüm beyin cerrahisi uzmanlık öğrencilerini içeren bir araştırmada da asistan el kitabı yokluğu, önemli bir eksiklik olarak dile getirilmiştir (21). Türkiye'de acil tıp uzmanlık eğitiminin değerlendirildiği bir anket çalışmasında ise (22), dahil edilen 20 bölümün 16'sında (\%80) asistan el kitabı kullanıldığ 1 saptanmıştır. Kulak burun boğaz hastalıkları asistanlarını içeren daha yeni bir anket çalışmasında ise bu oran \%67 olarak verilmektedir (23). Ancak mevcut durumda, sorunun eğitim programı veya asistan el kitabı yokluğundan çok etkin kullanıma dair yetersizlik ve isteksizlik ile bunların yapılandırma ve uygulama süreçlerinin şeffaflığındaki eksiklikler olduğu düşünülebilir.

Uzmanlık sonrası hastane içi eğitimde, fiziksel mekan koşulları ve imkanlar da önem taşımaktadır. Cerrahi dallarda sosyal desteğin fiziksel boyutu daha da önemli 
olabilir. Türkiye'de kulak burun boğaz hastalıkları uzmanlık öğrencilerin \%89'u eğitim sürecini “yorucu” ve \%70'i “stresli” olarak tanımlamaktadır (23). Cerrahi asistanlarının hastane nöbetlerindeki aktivitelerinin diğer bir "gölge asistan" tarafından değerlendirilmesine dayanan bir çalışmada, nöbet süresinin sadece \%30'unun hasta değerlendirme ile geçtiği; geri kalan zamanın ise uyku gibi günlük aktivitelere (\%35) ek olarak dosya hazırlama, iletişim ve tanısal değerlendirme gibi diğer işlere ayrıldığı saptanmıştır (24). Dolayısıyla, özellikle hastane nöbetleri sırasındaki hekimlerin ihtiyaçlarının karşılanması eğitim ortamına olumlu etki sağlayacaktır.

Mevcut çalışmamızın gerçekleştirildiği klinikte, özellikle nöbet odası başta olmak üzere bu açılardan eksikler mevcut olduğu söylenebilir. MESHEÖ, farklı maddelerde fiziksel eğitim koşullarının farklı boyutları hakkındaki algıların değerlendirilmesine imkan tanımaktadır. Örneğin, Brezilya'da gerçekleştirilen MESHEÖ Portekizce geçerlik çalışmasında en düşük ortalama skor $(1.2 \pm 1.3)$ nöbette çıkan yemekler hakkındaki algıya ait maddede saptanmıştır (25). Özet olarak, uzmanlık eğitiminde sosyal desteğin fiziksel boyutuna dair öğrenci algılarının periyodik olarak değerlendirilip geri bildirimler alınması ve eksikliklerin giderilmesi hedeflenmelidir (18).

Çalışma sonuçlarımızda açığa çıkan diğer bir durum ise, eğitim yılı (kıdem) arttıkça bazı ölçek maddelerinin puanlarındaki farklılıktır. Zaman temelli bu farkların asistan odası ve işten keyif alma gibi sosyal destek algılarında yoğunlaştığ1 söylenebilir. Amerika Birleşik Devletlerinde mezuniyet öncesi cerrahi staj öğrencilerini içeren bir takip çalışmasında ise stajın son haftalarında yaşam kalitesi ve uyku süresinin anlamlı olarak azaldığı saptanmıştır (26). Mezuniyet öncesi ve sonrası eğitimde ortam algısının zaman içinde değişiminin farklılık göstermesi söz konusudur. Mezuniyet öncesi stajlarda eğitimin sonuna doğru sosyal destek ihtiyacı artarken, uzmanlık eğitimin ilk yıllarında sosyal destek ön planda tutulabilir. Çalışmamızın bu açıdan kısıtlılı̆̆ı, takip içermemesi ve sadece kesitsel veri sağlamasıdır. İdeal olarak, ölçeğin belirli süre aralıklarında aynı katılımcılara tekrarlanması planlanmalıdır.

Türk Tabipler Birliği 20. Tıpta Uzmanlık Eğitim Kurultayı Sonuç Bildirgesinde Türkiye'de asistan eğitimine ayrılan zamanın yeterli olmadığı, görev tanımlamasının net olmadığı, iş yükünün eğitime engel olacak düzeyde olduğu ve standardizasyonun sağlanamadığ vurgulanmıştır (27). Ayrıca, nöbet sürelerinin üst sınırının net belirlenmediği ve yönetmeliğe aykırı olarak günaşırı nöbet tutulması uygulamasının devam ettiği saptamaları da anılan bildirgede yer almaktadır. Veri topladığımız klinikte de nöbet koşullarındaki sorunlara ek olarak nöbet sürelerinin de yasal sınır üzerine çıktığı görüşü öne çıkmaktadır.

Uzmanlık eğitiminde nöbet süresinin kısitlanması ve bunun etkileri, genel bir tartışma konusudur. Pakistan'da 2006 yılında yapılan bir anket çalışmasında, cerrahi uzmanlık öğrencileri haftada ortalama 100 saat çalıştıklarını belirtmiştir (28). Amerika Birleşik Devletlerinde 2007-2008 ulusal uzmanlik öğrencisi anket verilerinde, programların sadece \%37'sinde nöbet saatlerine dair herhangi bir olumsuz cevap verilmemiştir (29). Nöbet saatlerindeki azalmanın, uzmanlık öğrencilerinin yaşam kalitesinde ve eğitim programına bakış açısında olumlu algıda artışa yol açtığı saptanmıştır $(29,30)$. Buna 
rağmen, nöbet saatlerinin kısıtlanması ile hasta güvenliğinde veya asistan eğitim kalitesinde artış sağlanıp sağlanamayacağı konusu tartışma ve farklı dallarda araştırma konusu olmaya devam etmektedir (31-34).

Çalışmamızda, etnik ve cinsiyet ayrımcılık algısına dair maddelerden düşük ayrımcılık alg1s1 yönünde sonuçlar elde edildi. Ek olarak, ortalama ve toplam skorlar erkek ve kadın katılımcılar arasında benzerdi. Buna rağmen, etnik ayrımcılık için bir ve cinsiyet ayrımcılığı için iki katılımcının "katılıyorum" veya "kesinlikle katıllyorum" cevabı vermiş olması da dikkat çekicidir. Mevcut araştırma tasarımında etnik ve cinsiyet ayrımcılığ gibi hassas konularda sağliklı ve detaylı bilgi alınamayacağı açıktır. Literatürde hastane ortamında, özellikle cinsiyet ayrımcılığı ve taciz algısının nispeten yüksek olduğuna dair veriler mevcuttur (35-39). Türkiye'de tıpta uzmanlık eğitimi programlarındaki ayrımcılık konusunun nitel yöntemler kullanılarak ele alınması gereklidir.

Sonuç olarak, ölçeğin uygulandığı klinikte uzmanlık eğitimi alan hekimlerin hastane içi eğitime dair algıları cinsiyetten bağımsız olarak genelde olumlu gözükmekle birlikte asistan el kitabı, nöbet odası, çalışma saatleri başta gelmek üzere birçok mesleki özerklik ve sosyal destek unsurunda iyileştirmelere ihtiyaç duyulmaktadır. MESHEÖ, ülke veya hastane çapında uzmanlık öğrencilerinin algılarının genel değerlendirilmesini sağlayabileceği gibi $(12,13,15,16)$ çalışmamızda gösterdiğimiz üzere orta ölçekli kliniklerde de kullanımı ile kayda değer veri elde edilmesi mümkün gözükmektedir. MESHEÖ nispeten kolay uygulanabilir, kullanışlı ve güvenilir bir araç olarak uzmanlık öğrencilerine belirli aralıklarla uygulanarak mezuniyet sonrası eğitim programlarını değerlendirme ve iyileştirme amaçlı kullanılabilir.

\section{KAYNAKLAR}

1. Al-Ayed IH, Sheik SA. Assessment of the educational environment at the College of Medicine of King Saud University, Riyadh. East Mediterr Heal J. 2008;14(4):953-9.

2. Roff S, McAleer S. What is educational climate? Med Teach. 2001;23(4):333-4.

3. Farnan JM, Petty LA, Georgitis E, Martin S, Chiu E, Prochaska M, ve ark. A systematic review: The effect of clinical supervision on patient and residency education outcomes. Acad Med. 2012;87(4):428-42.

4. Smirnova A, Arah OA, Stalmeijer RE, Lombarts KMJMH, Van Der Vleuten CPM. The association between residency learning climate and inpatient care experience in clinical teaching departments in the netherlands. Acad Med. 2019;94(3):419-26.

5. Yılmaz D. Mezuniyet Sonrası Tıp eğitiminde öğrenme ortamı ve öğrenme iklimi. Türkiye Klin Med Educ Spec Top. 2016;1(2):1-7.

6. Roff S, McAleer S, Skinner A. Development and validation of an instrument to measure the postgraduate clinical learning and teaching educational environment for hospitalbased junior doctors in the UK. Med Teach. 2005;27(4):326-31.

7. Wall D, Clapham M, Riquelme A, Vieira J, Cartmill R, Aspegren K, ve ark. Is PHEEM a multi-dimensional instrument? An international perspective. Med Teach. 2009;31(11): e521-7. 
8. Balcıŏ̆lu H. Tıpta Uzmanlık Öğrencilerinin Eğitim Ortamı Algılamaları ve Buna Etkili Faktörlerin Değerlendirilmesi [Doktota Tezi]. Ankara Üniversitesi; 2008.

9. Piek J, Bossart M, Boor K, Halaska M, Haidopoulos D, Zapardiel I, ve ark. The work place educational climate in gynecological oncology fellowships across Europe: the impact of accreditation. Int J Gynecol Cancer. 2015;25(1):180-90.

10. Blazek BA, Zollinger TW, Look KY. Obstetrics-gynecology resident satisfaction. Am J Obstet Gynecol. 2005;193(5):1798-803.

11. Smirnova A, Ravelli ACJ, Stalmeijer RE, Arah OA, Heineman MJ, Van Der Vleuten CPM, ve ark. The association between learning climate and adverse obstetrical outcomes in 16 nontertiary obstetrics-gynecology departments in the Netherlands. Acad Med. 2017;92(12):1740-8.

\section{Akdeniz M, Yaman H, Şenol YY, Akbayin Z,} Cihan FG, Çelik S. Family practice in Turkey: Views of family practice residents. Postgrad Med. 2011;123(3):144-9.

13. Tastan K , Kuran E. Perceptions of family medicine assistants about education environment and factors affecting these perceptions. Konuralp Medical Journal. 2019; 11(2):171-6.

14. Rahimi M, Haghani F, Kohan S, Shirani M. The clinical learning environment of a maternity ward: A qualitative study. Women Birth. 2019;32(6):e523-e529.

Dr. Mekin Sezik.

15. Atılgan S, Teker G, Sezer B, Yeşiltepe M, Odabaşı O. Tıpta Uzmanlık Öğrencilerinin
Klinik Eğitim Ortamlarına İlişkin Algılarının Değerlendirilmesi. Ulusal Tıp Eğitimi Sempozyumu; 10-12 Nisan 2019; Eskişehir Türkiye [Özet bildiri].

16. Boor K, Scheele F, Van Der Vleuten CPM, Teunissen PW, Den Breejen EME, Scherpbier AJJA. How undergraduate clinical learning climates differ: A multi-method case study. Med Educ. 2008;42(10):1029-36.

17. Cate OT. Medical education in the Netherlands. Med Teach. 2007;29(8):752-7.

18. Byrne JM, Loo LK, Giang D. Monitoring and improving resident work environment across affiliated hospitals: A call for a national resident survey. Acad Med. 2009;84(2):199205.

19. Bourgain A, Ivorra-Deleuze D. Using the resident's log-book. Gynecol Obs Fertil. 2009;37(9):764.

20. Huri G, Cabuk YS, Gursoy S, Akkaya M, Ozkan S, Oztuna V, ve ark. Evaluation of the orthopaedics and traumatology resident education in Turkey: A descriptive study. Acta Orthop Traumatol Turc.2016;50(5):567-71.

21. Mateo-Sierra O, Delgado P, Cancela P, Fernández-Carballal C. Surgical activity by Spanish residents in neurosurgery under the Training Programme in place since 1984 and changes to be implemented under the New Training Programme. Acta Neurochir. 2005;147(4):449-56.

22. Aksay E, Sahin H, Kiyan S, Ersel M. Current status of emergency residency training programs in Turkey: After 14 years of experience. Eur J Emerg Med. 2009;16(1):4-10. 
23. Dokuzlar U, Miman MC, Ilter Denizoglu I, Egrilmez M. Opinions of otorhinolaryngology residents about their education process. Turkish Arch Otolaryngol. 2015;53(3):100-7.

24. Morton JM, Baker CC, Farrell TM, Yohe ME, Kimple RJ, Herman DC, ve ark. What do surgery residents do on their call nights? Am J Surg. 2004;188(3):225-9.

25. Vieira JE. The postgraduate hospital educational environment measure (PHEEM) questionnaire identifies quality of instruction as a key factor predicting academic achievement. Clinics. 2008;63(6):741-6.

26. Goldin SB, Wahi MM, Farooq OS, Borgman HA, Carpenter HL, Wiegand LR, ve ark. Student quality-of-life declines during third year surgical clerkship. J Surg Res. 2007;143(1):151-7.

\section{Türk Tabipler Birliği 20. Tıpta Uzmanlık} Eğitimi Kurultayı Uzmanlık Öğrencisi ve Genç Uzman Toplantısı Sonuç Bildirgesi; 13 Aralık 2014; Ankara. [https://www.toraks.org.tr/ userfiles/file/TTBTUEK2014.pdf].

28. Avan BI, Syed AR, Khokhar S, Awan F, Sohail N, Rashid S, Hamza H. Residents' perceptions of work environment during their postgraduate medical training in Pakistan. J Postgr Med. 20066;52(1):11-6.

29. Holt KD, Miller RS, Philibert I, Heard JK, Nasca TJ. Residents' perspectives on the learning environment: Data from the accreditation council for graduate medical education resident survey. Acad Med. 2010;85(3):512-8.

30. Immerman I, Kubiak E, Zuckerman J. Resident work-hour rules: a survey of residents' and program directors' opinions and attitudes. Am J Orthop. 2007;36(12):E172-9.
31. Swide CE, Kirsch JR. Duty hours restriction and their effect on resident education and academic departments: The American perspective. Curr Opin Anaesthesiol. 2007;20(6):580-4.

32. Philibert I. What is known: Examining the empirical literature in resident work hours using 30 influential articles. J Grad Med Educ. 2016;8(5):795-805.

33. Weiss P, Kryger M, Knauert M. Impact of extended duty hours on medical trainees. Sleep Heal. 2016;2(4):309-15.

34. Sandefur BJ, Shewmaker DM, Lohse CM, Rose SH, Colletti JE. Perceptions of the 2011 ACGME duty hour requirements among residents in all core programs at a large academic medical center. BMC Med Educ. 2017;17(1):1-9.

35. Camargo A, Liu L, Yousem DM. Sexual harassment in radiology. J Am Coll Radiol. 2017;14(8):1094-9.

36. Chrysafi P, Simou E, Makris M, Malietzis G, Makris GC. Bullying and sexual discrimination in the Greek health care system. J Surg Educ. 2017;74(4):690-7.

37. Kerr H, Armstrong L, Cade J. Barriers to becoming a female surgeon and the influence of female surgical role models. Postgr Med J. 2016;92(1092):576-80.

38. Young-Shumate L, Kramer T, Beresin E. Pregnancy during graduate medical training. Acad Med. 1993;68(10):792-9.

39. Garrison CB. The lonely only: Physician reflections on race, bias, and residency program leadership. Fam Med. 2019;51(1):59-60. 
Tablo 1. Mezuniyet Sonrası Hastane Eğitim Ortamı Ölçeği maddelerine verilen yanıtların alt ölçek başlıklarına göre dağılımı ve puanları

\begin{tabular}{|c|c|}
\hline Ölçek Maddesi & $\begin{array}{c}\text { Ortalama puan } \\
\text { ortalama } \pm \text { standart sapma } \\
\text { ortanca (dağlım) } \\
n=18 \\
\end{array}$ \\
\hline \multicolumn{2}{|l|}{ Ölçek Boyutu; Özerklik } \\
\hline 30. Asistanlık dönemime uygun mesleki (pratik, klinik) becerileri kazanma firsatım var & $\begin{array}{c}2.77 \pm 0.94 \\
3.0(0-4)\end{array}$ \\
\hline 5. Çalıștığım klinikteki sorumluluğum seviyeme uygundur & $\begin{array}{c}2.72 \pm 1.01 \\
3.0(0-4)\end{array}$ \\
\hline 29. Kendimi burada çalıșan ekibin bir parçası gibi hissediyorum & $\begin{array}{c}2.55 \pm 1.14 \\
3.0(0-4)\end{array}$ \\
\hline 8. Bilgi ve becerime uygun olmayan görevleri de yerine getirmek zorundayım* & $\begin{array}{c}2.50 \pm 1.20 \\
3.0(0-4)\end{array}$ \\
\hline 18. Hastalara sunduğum hizmetin sonuçlarını izleme fırsatım var & $\begin{array}{c}2.44 \pm 1.04 \\
3.0(0-4) \\
\end{array}$ \\
\hline 40. Klinik eğiticilerim karşılıklı saygıya dayanan bir çalıșma ortamı sağlarlar & $\begin{array}{c}2.44 \pm 0.92 \\
3.0(0-4) \\
\end{array}$ \\
\hline 34. Burada aldığım eğitim bana iyi bir uzman hekim olacağımı hissettiriyor & $\begin{array}{c}2.38 \pm 1.14 \\
3.0(0-4)\end{array}$ \\
\hline 1. Uzmanlık eğitimime başlarken çalışma saatlerim hakkında bilgilendirildim & $\begin{array}{c}2.00 \pm 1.37 \\
2.5(0-4)\end{array}$ \\
\hline 11. Gereksiz yere göreve çağırılırım* & $\begin{array}{c}1.88 \pm 1.18 \\
2.0(0-4)\end{array}$ \\
\hline 32. İş yüküm bence uygun & $\begin{array}{c}1.77 \pm 1.11 \\
2.0(0-3) \\
\end{array}$ \\
\hline 14. Bu klinikte uygulanacak tanı ve tedavi protokolleri açık biçimde tanımlanmıștır & $\begin{array}{c}1.66 \pm 0.97 \\
2.0(0-3)\end{array}$ \\
\hline 4. Uzmanlık eğitimine başlarken uyum eğitimi yapıldı & $\begin{array}{c}1.50 \pm 1.20 \\
1.5(0-3)\end{array}$ \\
\hline 17. Çalışma saatlerim haftalık yasal çalışma süresi ile uyumludur** & $\begin{array}{c}1.00 \pm 1.49 \\
0.0(0-4)\end{array}$ \\
\hline 9. Bilgilendirici bir asistan el kitabı vardır** & $\begin{array}{c}0.61 \pm 0.91 \\
0.0(0-3) \\
\end{array}$ \\
\hline \multicolumn{2}{|l|}{$\begin{array}{ll} & \text { Ölçek Boyutu; Eğitim } \\
\end{array}$} \\
\hline 6. Her zaman kıdemli gözetiminde desteklenerek çalışırım & $\begin{array}{c}2.72 \pm 0.89 \\
3.0(0-3)\end{array}$ \\
\hline 28. Klinik eğiticilerimin eğitim ve öğretim becerileri iyidir & $\begin{array}{c}2.72 \pm 0.89 \\
3.0(1-4)\end{array}$ \\
\hline 31. Klinik eğiticilerime ihtiyacım olduğunda kolayca ulaşabiliyorum & $\begin{array}{c}2.66 \pm 1.13 \\
3.0(0-4)\end{array}$ \\
\hline 22. Kıdemlilerimden düzenli olarak geribildirim alırım & $\begin{array}{c}2.61 \pm 0.84 \\
2.5(1-4) \\
\end{array}$ \\
\hline 27. Gereksinimlerime yönelik yeterli klinik öğrenme fırsatım var & $\begin{array}{c}2.50 \pm 1.20 \\
3.0(0-4)\end{array}$ \\
\hline 33. Klinikteki kıdemlilerim öğrenme firsatlarını iyi değerlendirirler & $\begin{array}{c}2.44 \pm 1.14 \\
3.0(0-4)\end{array}$ \\
\hline 39. Klinik eğiticilerim güçlü ve zayıf yanlarımı bana uygun biçimde söylerler & $\begin{array}{c}2.27 \pm 1.36 \\
3.0(0-4)\end{array}$ \\
\hline 10. Klinik eğiticilerimin iletişim becerileri iyidir & $\begin{array}{c}2.27 \pm 1.27 \\
2.5(0-4)\end{array}$ \\
\hline 23. Klinik eğiticilerim planlı programlı çalıșır & $\begin{array}{c}2.27 \pm 1.01 \\
2.0(0-4)\end{array}$ \\
\hline 37. Klinik eğiticilerim kendi kendine öğrenme konusunda beni teşvik eder & $\begin{array}{c}2.22 \pm 1.00 \\
2.5(0-3)\end{array}$ \\
\hline 2. Klinik eğiticilerim beklentilerini açıkça söylerler & $\begin{array}{c}2.00 \pm 1.32 \\
2.0(0-4)\end{array}$ \\
\hline 15. Klinik eğiticilerim işlerini șevkle, hevesle yaparlar & $\begin{array}{c}1.88 \pm 1.18 \\
2.0(0-4) \\
\end{array}$ \\
\hline 12. Eğitim programlarına etkin biçimde katılabiliyorum & $\begin{array}{c}1.66 \pm 1.37 \\
1.5(0-4) \\
\end{array}$ \\
\hline 21. Gereksinimlerime uygun bir eğitim programı vardır & $1.61 \pm 1.14$ \\
\hline
\end{tabular}




\begin{tabular}{|c|c|}
\hline & $2.0(0-3)$ \\
\hline 3. Çalıştığım klinikte eğitimime zaman ayırabiliyorum & $\begin{array}{c}1.50 \pm 1.20 \\
1.5(0-3) \\
\end{array}$ \\
\hline \multicolumn{2}{|l|}{ Ölçek Boyutu; Sosyal Destek } \\
\hline 7. Bu klinikte etnik ayrımcllk vardır* & $\begin{array}{c}3.38 \pm 1.03 \\
4(0-4)\end{array}$ \\
\hline 16. Benimle aynı kıdemdekilerle işbirliği ve uyum içinde çalışabiliyorum & $\begin{array}{c}2.83 \pm 0.85 \\
3.0(1-4) \\
\end{array}$ \\
\hline 26. Nöbette çıkan yemekler iyidir & $\begin{array}{c}2.77 \pm 1.06 \\
3.0(1-4) \\
\end{array}$ \\
\hline 13. Çalıştı̆ım klinikte cinsiyet ayrımcıllğı yapılmaktadır* & $\begin{array}{c}2.72 \pm 1.12 \\
3.0(0-4)\end{array}$ \\
\hline 35. Klinik eğiticilerim aynı zamanda iyi birer danışman ve "akıl hocası"dır & $\begin{array}{c}2.44 \pm 1.19 \\
3.0(0-4)\end{array}$ \\
\hline 24. Bu hastane ortamında kendimi fiziksel olarak güvende hissediyorum & $\begin{array}{c}2.00 \pm 1.37 \\
2.0(0-4) \\
\end{array}$ \\
\hline 36. İşimden çok keyif alıyorum & $\begin{array}{c}2.00 \pm 1.18 \\
2.0(0-4)\end{array}$ \\
\hline 19. Mesleki kariyerime ilişkin uygun ve yeterli danışmanlık alabiliyorum & $\begin{array}{c}1.83 \pm 1.29 \\
2.0(0-4)\end{array}$ \\
\hline 25. Bu klinikte (uzmanlık eğitimi sırasında) asistanları suçlama alışkanlığı yoktur & $\begin{array}{c}1.72 \pm 1.31 \\
2.0(0-4)\end{array}$ \\
\hline 38. Eğitimini tamamlamada eksikliği olanlar için danışmanlık alabilecek firsatlar vardır & $\begin{array}{c}1.50 \pm 0.98 \\
1.5(0-3)\end{array}$ \\
\hline 20. Bu hastanede asistanlar için yeterli ve uygun asistan odası (özellikle de nöbet odası) vardı̈** & $\begin{array}{c}0.89 \pm 1.28 \\
0.0(0-3)\end{array}$ \\
\hline
\end{tabular}

Madde önündeki numara maddenin ölçekteki sırasımı göstermektedir.

* Olumsuz anlam yükü içeren dört madde için ayna görüntüsü şeklinde ters puanlama yapılmaktadır.

** Ortalama bir ve altında puan verilen maddeler

Tablo 2. Ölçek alt grup skorları

\begin{tabular}{|l|c|c|c|c|c|}
\hline \multirow{2}{*}{ BOYUT } & \multirow{2}{*}{$\begin{array}{c}\text { Ortalama toplam skor } \\
(\mathbf{n = 1 8})\end{array}$} & $\begin{array}{c}\text { Kadın } \\
(\mathbf{n}=\mathbf{9})\end{array}$ & Erkek (n=8) & Kidemli (n=6) & Kıdemsiz (n=11) \\
\cline { 3 - 6 } & & $27.8 \pm 7.6$ & $29.3 \pm 9.6$ & $32.1 \pm 10.9$ & $25.6 \pm 5.8$ \\
\hline Özerklik & $28.3 \pm 8.2$ & $28.0(15-36)$ & $28.5(14-47)$ & $34.0(14-47)$ & $26.0(15-35)$ \\
\hline Nitelik & $28.0(14-47)$ & $34.7 \pm 9.8$ & $32.5 \pm 13.4$ & $39.7 \pm 14.3^{\text {a }}$ & $29.5 \pm 7.9$ \\
& $33.4 \pm 11.0$ & $38.0(20-46)$ & $29.0(13-55)$ & $42.5(13-55)$ & $29.0(20-44)$ \\
\hline Sosyal destek & $24.5(13-55)$ & $24.4 \pm 6.9$ & $24.1 \pm 7.5$ & $28.5 \pm 8.4^{\mathbf{b}}$ & $21.2 \pm 4.5$ \\
& $24.0(12-36)$ & $25.0(12-35)$ & $23.0(14-36)$ & $30.5(14-36)$ & $23.0(12-28)$ \\
\hline Toplam & $85.8 \pm 24.8$ & $86.9 \pm 22.8$ & $86.0 \pm 29.7$ & $100.3 \pm 33.1^{\mathbf{c}}$ & $76.4 \pm 15.9$ \\
& $83.5(41-138)$ & $95.0(49-117)$ & $79.0(41-138)$ & $136.5(41-138)$ & $76.0(49-105)$ \\
\hline
\end{tabular}

Hücrelerde, ilk satırda ortalama \pm standart sapma, ikinci satırda ortanca (dağılım) verilmiştir.

Birer formda cinsiyet ve kıdem belirtilemediğinden, bunlar analiz dışı bırakılmıștır.

Mann-Whitney testi ile karş1laştırmalar: ${ }^{\mathrm{a}} \mathrm{p}=0.070 ;{ }^{\mathrm{b}} \mathrm{p}=0.039 ;{ }^{\mathrm{c}} \mathrm{p}=0.087$. Tüm diğer karşılaştırmalarda $\mathrm{p}>0.05$ 